Nat. Hazards Earth Syst. Sci., 19, 715-719, 2019

https://doi.org/10.5194/nhess-19-715-2019

(C) Author(s) 2019. This work is distributed under the Creative Commons Attribution 4.0 License.

\title{
Brief communication: Rethinking the 1998 China floods to prepare for a nonstationary future
}

\author{
Shiqiang Du ${ }^{1,2}$, Xiaotao Cheng ${ }^{3}$, Qingxu Huang ${ }^{4}$, Ruishan Chen ${ }^{5}$, Philip J. Ward ${ }^{2}$, and Jeroen C. J. H. Aerts ${ }^{2}$ \\ ${ }^{1}$ School of Environmental and Geographical Sciences, Shanghai Normal University, Shanghai, 200234, China \\ ${ }^{2}$ Institute for Environmental Studies, Vrije Universiteit Amsterdam, Amsterdam, $1081 \mathrm{HV}$, the Netherlands \\ ${ }^{3}$ China Institute of Water Resources and Hydropower Research, Beijing, 100038, China \\ ${ }^{4}$ State Key Laboratory of Earth Surface Processes \& Resource Ecology, Beijing Normal University, Beijing, 100875, China \\ ${ }^{5}$ School of Geographic Sciences, East China Normal University, Shanghai, 200241, China
}

Correspondence: Shiqiang Du (shiqiangdu@shnu.edu.cn) and Jeroen C. J. H. Aerts (jeroen.aerts@vu.nl)

Received: 20 December 2018 - Discussion started: 7 January 2019

Revised: 21 March 2019 - Accepted: 23 March 2019 - Published: 2 April 2019

\begin{abstract}
A mega-flood in 1998 caused tremendous losses in China and triggered major policy adjustments in floodrisk management. This paper aims to retrospectively examine these policy adjustments and discuss how China should adapt to newly emerging flood challenges. We show that China suffers annually from floods despite large-scale investments and policy adjustments. Rapid urbanization and climate change will exacerbate future flood risk in China, with cascading impacts on other countries through global trade networks. Therefore, novel flood-risk management approaches are required, such as a risk-based urban planning and coordinated water governance systems with public participation, in addition to traditional structural protection.
\end{abstract}

\section{China's mega-flood in 1998}

In 1998, a mega-flood swept through China's major river basins, including the Yangtze, Songhua, Nen, Min, and Pearl rivers. In the Yangtze and Songhua rivers, floodwaters exceeded historical maximum heights, overtopped $300 \mathrm{~km}$ of dikes, and led to 15000 dike segments being put in an emergency state and having to be reinforced by 8 million rescuers. Nationwide, the floods affected 186 million people, caused 4150 deaths, and led to total economic losses of USD 70 billion (in 2015 USD) (MWR, 1999). While the mega-flood of 1998 had particularly severe impacts, the 1990s also saw large losses. On average, economic damages from floods in the 1990s were around USD 40 billion per year, accounting for $2.3 \%$ of China's GDP (Fig. 1a).

The main drivers of the disastrous 1998 flood are considered to be land use change and poor maintenance of levees, as well as extreme weather conditions (MWR, 1999). With respect to land use change, China extensively exploits its land to feed $21 \%$ of the world's population, while having only $6 \%$ of the world's total water resources and $9 \%$ of the world's arable land. This has resulted in a rapid degradation of the forested upper catchments, disrupting the functioning of reservoirs through enhanced peak flows and increased soil erosion. In the middle and lower reaches, wetlands and waterbodies have been reclaimed as polders for farmlands or fishponds. As a result, the capacity of wetlands and waterbodies to store and to convey floodwaters has declined. Furthermore, to protect polders against rising floodwaters, lakes and tributaries have been further disconnected from river channels by floodgates. For example, the lake surface area connected to the Yangtze River reduced from $17198 \mathrm{~km}^{2}$ in the $1950 \mathrm{~s}$ to $6000 \mathrm{~km}^{2}$ in 1998 - this led to increased floodwater levels in 1998 by approximately $1 \mathrm{~m}$ (MWR, 1999). This paper aims to retrospectively examine policy adjustments taken following the 1998 floods and discuss how China should adapt to newly emerging flood challenges. 

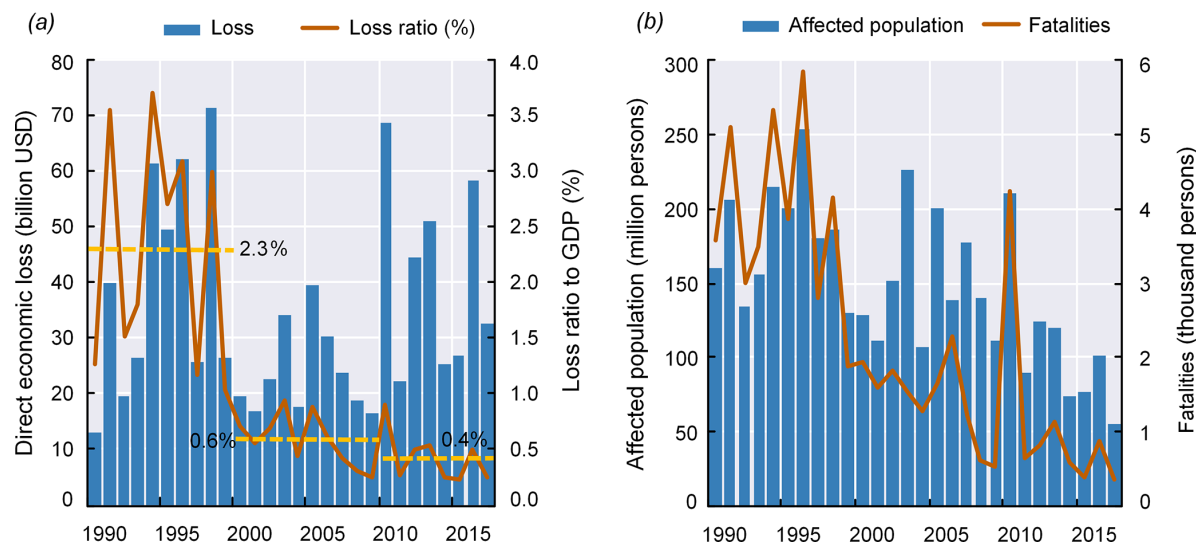

Figure 1. Flood losses (a, in 2015 USD) and flood fatalities (b) in China from 1990 to 2017 (Data source: MWR, 2017).

\section{China's response to the 1998 flood}

In response to the 1998 mega-flood, China adopted a series of integrated flood management policies, focusing on three major issues: (1) conserving soil and water through forest protection and reforestation, (2) returning reclaimed lands to open waters and wetlands, and (3) enhancing both levee and reservoir systems to increase flood protection and control. In the years after the 1998 flood, 16 major sustainability programs were launched (Bryan et al., 2018). For instance, the Grain for Green Program (1999-2020) aims to prevent soil erosion and mitigate flooding by converting cropland and wasteland on hillslopes into natural forests and grasslands. The programs related to runoff and erosion invested a total of USD 114.2 billion between 1998 and 2015, accounting for $32.5 \%$ of the total sustainability program investment (Bryan et al., 2018). These efforts reduced soil erosion by $12.9 \%$ nationwide, $58.8 \%$ in the Yangtze River basin, and $27.0 \%$ in the Yellow River basin between 2000 and 2010 (Deng et al., 2012). Furthermore, the capacity of wetlands to temporarily store floodwaters increased by $12.7 \%$ (Ouyang et al., 2016).

China also required local communities to convert polders into wetland areas and lakes for capturing floodwaters. From 1998 to 2002, 1461 polders were removed and 2.4 million people were relocated elsewhere in the Yangtze River basin. This increased the inland water area by $2900 \mathrm{~km}^{2}$ and added a storage capacity of 13 billion cubic meters (MWR, 2015). However, efforts to restore and protect open waters, such as lakes and ponds, deteriorated over time and by 2015 there were still 406 polders in the main channels of Yangtze River and 133 polders in the Dongting and Poyang lake regions, with a total population of 1.9 million (MWR, 2015). Nationwide, the population living in floodplains increased by $1.1 \%$ per year over the period 1990-2015, which is much faster than the population growth outside floodplains $(0.4 \%$ per year) (Fang et al., 2018).

The impact of the 1998 floods also led to a new flood protection program. China invested a total of USD 294 billion

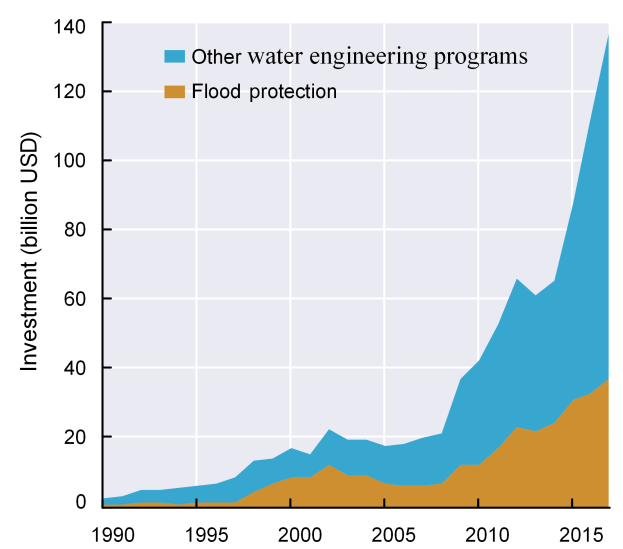

Figure 2. Investment in flood protection and other water engineering programs (e.g., water supply and hydropower) in China (in 2015 USD; data source: MWR, 2017).

on structural protection during 1998-2017, accounting for more than a third of total investments in water engineering, which also include water supply and hydropower generation (Fig. 2). As a result, the lengths of the river banks protected by well-maintained dikes increased from $76532 \mathrm{~km}$ in 1998 to $201124 \mathrm{~km}$ in 2016 and reservoir capacity increased from 493 trillion to 897 trillion cubic meters (MWR, 2017). An example of the latter is the well-known Three Gorges Dam, which was completed in 2006 and has a capacity of 39.3 billion cubic meters. At Jingzhou, a weak point in the Yangtze river downstream from the dam, the protection standard was increased from a 10-year to a 100-year flood (Mei, 2010).

Finally, China has also made huge efforts to improve evacuation. In the 2010s, China evacuated an average of 9.9 million people per year and called in 10.8 million rescuers for emergencies. For example, 190000 people were evacuated from Shanghai for Typhoon Anbi on 22 July 2018. 


\section{Societal effects of response measures after 1998}

The flood management efforts taken after the 1998 flood initially decreased the annual flood fatalities from 3909 in the 1990 s to 1454 in the 2000 s, but the number leveled off at 1134 in the 2010s (Fig. 1b). Medium- and smallsized basins disproportionally suffer flood fatalities, with 15662 deaths in the 2010s (72.6\% of the total flood fatalities in China) (MWR, 2017). For instance, a local-scale catastrophe in Zhouqu, western China, led to 1765 fatalities on 8 August 2010, marking 2010 as the worst year since 1998 in terms of flood fatalities.

Furthermore, despite the large investments in flood management, flood damage reached a new peak during the 2010s (Lyu et al., 2018b): USD 41.1 billion per year. This exceeds the long-term average annual damage of USD 24-39 billion in the 1990s-2000s (in 2015 USD; Fig. 1a). While the ratio of economic losses from flooding to GDP decreased from $2.3 \%$ in the 1990 s to $0.6 \%$ in the 2000 s and to $0.4 \%$ in the $2010 \mathrm{~s}$, the current loss ratio $(0.4 \%)$ is much larger than that in high-income countries (e.g., $<0.05 \%$ in the USA, Pielke, 2013). Floods have annually hit about 157 cities since 2006 and this number is increasing. Flood events in highly urbanized areas have caused large indirect economic ripple effects, and there are recent examples of paralyzed cities in China due to flood impacts on critical infrastructure (Lyu et al., 2018a). In recent years, this has interrupted $\sim 40000$ factories per year, affected electricity supply $\sim 20000$ times, and shut down 166 airports and seaports (MWR, 2017).

\section{Future challenges to flood management in China}

It is expected that future urbanization and climate change will further increase economic flood damage by $263 \%-$ $331 \%$ in the Yangtze River basin from 2010 to 2080 (Winsemius et al., 2016). For China as a whole, it is expected that economic-production losses from floods will increase more rapidly than other countries (Willner et al., 2018). If the world's second largest economy continues suffering huge amounts of flood damage, the impact could be felt worldwide and may hamper the global economy. During 2016-2035, China is expected to suffer two-thirds of the global direct production losses caused by floods, totalling USD 389 billion, which can further propagate an indirect impact of about USD 300 billion to other countries through the global trade and supply network (Willner et al., 2018).

Flood management in China and in urban areas in particular could be better prepared for these future challenges. Urbanization in Chinese floodplains continues to increase, and $80.0 \%$ of China's total population is projected to live in cities by 2050 , which represents an increase from $33.5 \%$ in 1998 and $55.5 \%$ in 2015. Urban land in floodplains has expanded at a rate of $1210 \mathrm{~km}^{2} \mathrm{yr}^{-1}$ between 1998 and 2015 and is expected to increase by another $16900 \mathrm{~km}^{2}$ by 2050 (Du et al.,
2018). These numbers will probably be even higher due to the ending of the "one-child" policy.

Another challenge is to ensure that flood protection standards keep up with the rate of urbanization and climate change. A survey in 2013 showed that $50 \%$ (or 321) of the 642 Chinese cities did not reach the required flood protection standards and that $44 \%$ (or 284) of the cities did not complete or update flood management plans (Fang et al., 2018). This especially holds true for cities in the semiarid northwestern part of China, which have a slower economic development and generally limited flood protection. However, many of those cities are rapidly growing in the floodplains (Du et al., 2018; Fang et al., 2018) and are expected to experience increasing extreme precipitation events (Zhou et al., 2014). The floods in Lanzhou, Ningxia, and Xining in 2017 and 2018 are wake-up calls about rising flood risk in this area.

\section{Future adaptation}

Novel flood adaptation policies are required to address these (uncertain) future challenges. Such policies should be based on a well-established and up-to-date risk assessment, which accounts for future changes in climate and socioeconomic conditions. One component of the new policies could be enhanced flood protection systems, especially in urban areas with high economic values and large exposed populations (Ward et al., 2017). However, structural measures can also cause the "levee effect", further stimulating exposure in protected areas. Hence, additional measures and regulations are required to solve this paradox between urban development and structural protection, to sustain and enhance environmental values, and to reduce flood risk in areas where dikes are not cost-effective.

\subsection{Integrating flood management into urban planning}

The 1998 floods triggered a large-scale conversion of farmlands and settlements to wetlands and inland water areas, which was unprecedented in this populous country. However, the awareness gained in the aftermath of the 1998 catastrophe seems to be dissipating over time: cities are again reclaiming lands from natural floodplains and urban exposure is again rising in vulnerable areas (Lyu et al., 2018b). New spatial-planning policies, such as zoning and building codes, could be developed and reinforced to reduce local flood risk, involving households and communities. In addition, the importance of ecosystems and "nature-based solutions" should be increasingly acknowledged in reducing flood risk (Lyu et al., 2018b). For this latter aspect, China has nominated 1060000 "river chiefs" to protect the natural processes of storing and discharging floodwaters from expanding cities. Balancing the huge development pressure and restoring spaces for floodwaters is a challenge but is critical 
for integrating flood management into urban planning (Opperman et al., 2009).

\subsection{Strengthen governance and coordination}

Another challenge is to improve the development of integrated flood risk management plans and designs, preferably involving all responsible stakeholders (Aerts et al., 2014). However, flood risk management in China is still characterized by a top-down administration that is divided among different governmental organizations. At national level, for instance, dike design and maintenance is the responsibility of the MWR, wetland protection is managed by the Ministry of Ecology and Environment, the land use master plan falls within the realm of the Ministry of Natural Resources, and the urban-oriented "Sponge City" program is coordinated by the Ministry of Housing and Urban-Rural Development. In this multi-jurisdiction setting, a new governance structure is needed to effectively coordinate water and soil conservation, wetland protection, dike design, and urban planning for reducing flood risk (Cheng et al., 2018). Such a new governance system should address decentralized governance approaches, involving the heterogeneities of China's communities. Furthermore, attention should be paid to resolve upstream and downstream conflicts and differences in protection levels between urban and rural areas (Cheng et al., 2018).

\subsection{Improve information sharing and public participation}

Flood risk information that is available to the public is currently scarce in China. Flood hazard maps were produced during 2011-2016, and China plans to invest in highresolution flood information, for example from remote sensing. The sharing of flood risk information, as recommended by the United Nations International Strategy for Disaster Reduction Sendai Framework, facilitates public participation and stimulates a "bottom-up" process to raise awareness and promote local action for flood adaptation (Haer et al., 2019). In addition, the information on the cost and benefit of wet and/or dry flood-proofing buildings and other flood adaptation measures must be improved, to demonstrate what local stakeholders can do themselves in terms of flood adaptation. Public participation can also support policy makers in developing adaptation measures that have support from the public.

Data availability. Data are available upon request by contacting the corresponding author (shiqiangdu@outlook.com).

Author contributions. All authors contributed to the preparation of this paper.
Competing interests. The authors declare that they have no conflict of interest.

Acknowledgements. This research was funded by the National Natural Science Foundation of China (grant nos. 41871200, 41730642, 51761135024) and the National Key Research and Development Program of China (2017YFC1503001). Jeroen C. J. H. Aerts and Philip J. Ward received additional support from the Netherlands Organisation for Scientific Research (NWO) in the form of VICI grant 453.140.006 and VIDI grant 016.161.324, respectively. We are grateful to Anders Levermann at the Potsdam Institute for Climate Impact Research, Germany, for providing the propagation effect of China's production loss to the rest of the world.

Review statement. This paper was edited by Sven Fuchs and reviewed by two anonymous referees.

\section{References}

Aerts, J., Botzen, W. J. W., Emanuel, K., Lin, N., de Moel, H., and Michel-Kerjan, E. O.: Evaluating Flood Resilience Strategies for Coastal Megacities, Science, 344, 472-474, https://doi.org/10.1126/science.1248222, 2014.

Bryan, B. A., Gao, L., Ye, Y., Sun, X., Connor, J. D., Crossman, N. D., Stafford-Smith, M., Wu, J., He, C., Yu, D., Liu, Z., Li, A., Huang, Q., Ren, H., Deng, X., Zheng, H., Niu, J., Han, G., and Hou, X.: China's Response to a National Land-System Sustainability Emergency, Nature, 559, 193-204, https://doi.org/10.1038/s41586-018-0280-2, 2018.

Cheng, X., Wan, H., Huang, S., Li, C., and Zhang, H.: Lessons Learned from the 2016 Yangtze River Flood in Anhui Province, China, Int. J. River Basin Manage., 16, 307-314, https://doi.org/10.1080/15715124.2018.1437741, 2018.

Deng, L., Shangguan, Z.-P., and Li, R.: Effects of the Grain-forGreen Program on Soil Erosion in China, Int. J. Sediment Res., 27, 120-127, https://doi.org/10.1016/S1001-6279(12)60021-3, 2012.

Du, S., He, C., Huang, Q., and Shi, P.: How Did the Urban Land in Floodplains Distribute and Expand in China from 1992-2015?, Environ. Res. Lett., 13, 034018, https://doi.org/10.1088/17489326/aaac07, 2018.

Fang, Y., Du, S., Scussolini, P., Wen, J., He, C., Huang, Q., and Gao, J.: Rapid Population Growth in Chinese Floodplains from 1990 to 2015, Int. J. Environ. Res. Publ. Health, 15, 1602, https://doi.org/10.3390/ijerph15081602, 2018.

Haer, T., Botzen, W. J. W., and Aerts, J. C.: Advancing Disaster Policies by Integrating Dynamic Adaptive Behaviour in Risk Assessments Using an Agent-Based Modelling Approach, Environ. Res. Lett., https://doi.org/10.1088/1748-9326/ab0770, in press, 2019.

Lyu, H.-M., Sun, W.-J., Shen, S.-L., and Arulrajah, A.: Flood Risk Assessment in Metro Systems of Mega-Cities Using a GISBased Modeling Approach, Sci. Total Environ., 626, 1012-1025, https://doi.org/10.1016/j.scitotenv.2018.01.138, 2018a.

Lyu, H.-M., Xu, Y.-S., Cheng, W.-C., and Arulrajah, A.: Flooding Hazards across Southern China and Prospec- 
tive Sustainability Measures, Sustainability, 10, 1682, https://doi.org/10.3390/su10051682, 2018b.

Mei, J.: Flood Control Planning and Construction in China, China Water Resour., 20, 17-19, 2010.

MWR: The 1998 China Flood, China Water Power Press, Beijing, 1999.

MWR: Flood Prevention Plan of Yangtze River, Ministry of Water Resources, Beijing, 14 pp. ,available at: http://www.cjw.gov.cn/ xwzx/ztjjx/zjfyhsfa (last access: 6 June 2018), 2015.

MWR: China Water Statistical Yearbook 2017, China Water Power Press, Beijing, 2017.

Opperman, J. J., Galloway, G. E., Fargione, J., Mount, J. F., Richter, B. D., and Secchi, S.: Sustainable Floodplains through Large-Scale Reconnection to Rivers, Science, 326, 1487-1488, https://doi.org/10.1126/science.1178256, 2009.

Ouyang, Z., Zheng, H., Xiao, Y., Polasky, S., Liu, J., Xu, W., Wang, Q., Zhang, L., Xiao, Y., Rao, E., Jiang, L., Lu, F., Wang, X., Yang, G., Gong, S., Wu, B., Zeng, Y., Yang, W., and Daily, G. C.: Improvements in Ecosystem Services from Investments in Natural Capital, Science, 352, 1455-1459, https://doi.org/10.1126/science.aaf2295, 2016.
Pielke, R.: The Precipitous Decline in US Flood Damage as a Percentage of GDP, $13 \mathrm{pp}$., available at: https://theclimatefix.wordpress.com/2015/02/05/theprecipitous-decline-in-us-flood-damage-as-a-percentage (last access: 10 October 2018), 2013.

Ward, P. J., Jongman, B., Aerts, J. C. J. H., Bates, P. D. Botzen, W. J. W., Diaz Loaiza, A., Hallegatte, S., Kind, J. M., Kwadijk, J., Scussolini, P., and Winsemius, H. C.: A Global Framework for Future Costs and Benefits of River-Flood Protection in Urban Areas, Nat. Clim. Change, 7, 642-646, https://doi.org/10.1038/nclimate3350, 2017.

Willner, S. N., Otto, C., and Levermann, A.: Global Economic Response to River Floods, Nat. Clim. Change, 8, 594-598, https://doi.org/10.1038/s41558-018-0173-2, 2018.

Winsemius, H. C., Aerts, J. C. J. H., van Beek, L. P. H., Bierkens, M. F. P., Bouwman, A., Jongman, B., Kwadijk, J. C. J., Ligtvoet, W., Lucas, P. L., van Vuuren, D. P., and Ward, P. J.: Global Drivers of Future River Flood Risk, Nat. Clim. Change, 6, 381-385, https://doi.org/10.1038/nclimate2893, 2016

Zhou, B., Wen, Q. H., Xu, Y., Song, L., and Zhang, X.: Projected Changes in Temperature and Precipitation Extremes in China by the CMIP5 Multimodel Ensembles, J. Climate, 27, 6591-6611, https://doi.org/10.1175/jcli-d-13-00761.1, 2014. 